\title{
Abruption-Induced Preterm Delivery Is Associated with Thrombin-Mediated Functional Progesterone Withdrawal in Decidual Cells
}

\author{
Charles J. Lockwood, ${ }^{*}$ Umit A. Kayisli, ${ }^{*}$ \\ Carlos Stocco, ${ }^{\dagger}$ William Murk, ${ }^{+}$ \\ Emre Vatandaslar, ${ }^{\ddagger}$ Lynn F. Buchwalder, ${ }^{*}$ and \\ Frederick Schatz* \\ From the Department of Obstetrics and Gynecology,* Obio State \\ University College of Medicine, Columbus, Ohio; the Department \\ of Physiology and Biophysics, ${ }^{\dagger}$ College of Medicine, University of \\ Illinois at Chicago, Chicago, Illinois; and the Department of \\ Obstetrics, Gynecology and Reproductive Sciences, ${ }^{\ddagger}$ Yale \\ University School of Medicine, New Haven, Connecticut
}

Plasma progesterone levels remain elevated throughout human pregnancy, suggesting that reduced reproductive-tract progesterone receptor (PR) initiates labor. Placental abruption and excess thrombin generation elicit preterm delivery (PTD). PR, glucocorticoid receptor (GR), and total and p-ERK1/2 in decidual cells (DCs) and interstitial trophoblasts (IT) were assessed via immunohistochemical staining in abruption-associated PTD versus gestational-age matched control placentas, and in cultured DCs incubated with estradiol (E2) \pm medroxyprogesterone acetate (MPA) \pm thrombin. Immunostaining for PR was lower in DC nuclei in abruption versus control decidua and was absent from ITs; GR was higher in IT than DCs, with no abruption-related changes in either cell type; p-ERK1/2 was higher in DCs in abruption than control decidua, with total ERK 1/2 unchanged. Immunoblotting of cultured DCs demonstrated strong E2, weak MPA, and intermediate E2+MPA mediated elevation of PR-A and PR-B levels, with constitutive GR expression. In cultured DCs, thrombin inhibited PR but not GR mRNA levels, reduced PR binding to DNA and $\left[{ }^{3} \mathrm{H}\right]$ progesterone binding to PR, and enhanced phosphorylated but not total ERK1/2 levels. Coincubation with a specific p-ERK1/2 inhibitor reversed thrombin-enhanced $p$-ERK1/2 and lowered PR levels. Thus, abruption-associated PTD is initiated by functional progesterone withdrawal, as indicated by significantly reduced DC nuclear expression of PR-A and PR-B. Functional withdrawal of progesterone results in increased $p$-ERK1/2, and is thus one pathway initiating abruption-associated PTD. (Am J Pathol 2012, 181: 2138-2148; http://dx.doi.org/10.1016/j.ajpath.2012.08.036)

During human pregnancy, bleeding into the decidua basalis (abruption) can occur either as a concealed abruption or as vaginal bleeding or retrochorionic hematoma formation. Vaginal bleeding in more than one trimester is associated with a sevenfold increased risk of preterm premature rupture of the membranes (PPROM) ${ }^{1-3}$ The association between abruption and PPROM is particularly strong between 22 and 32 weeks. During this period, abruption occurs in $37.5 \%$ of PPROM cases, compared with $0.8 \%$ of patients with term delivery $(P<0.01) .{ }^{4}$ Ischemic placental diseases associated with pre-eclampsia and idiopathic fetal growth restriction also accompany half of all preterm deliveries (PTDs), with or without abruption. ${ }^{1}$ The primary defect in these cases is shallow endovascular trophoblast invasion of the decidua resulting in impaired remodeling of the spiral arteries. ${ }^{1,5}$ Other placental lesions associated with abruption include spiral artery thrombosis ${ }^{4}$ and sclerotic lesions in myometrial arteries. ${ }^{6}$ Inherited thrombophilias also appear to be linked to abruption. ${ }^{7}$ Women experiencing an abruption face long-term health risks. $^{8}$

During the luteal phase of the human menstrual cycle, progesterone (P4) stimulates estradiol (E2)-primed human endometrial stromal cells to decidualize and express tissue factor (TF), ${ }^{9}$ a transmembrane $45-\mathrm{kDa}$ glycoprotein. Vascular injury initiates clotting as a consequence of binding of plasma-derived factor VII to perivascular cell membrane-bound TF. The resulting TF/NIIa complex promotes hemostasis by cleaving prothrombin to thrombin, which converts fibrinogen to fibrin and activates platelets to

Supported by NIH grant R01-HD33937-12 (C.J.L.) and the Prematurity Research Initiative Program of the March of Dimes Foundation (21-FY051249 to C.J.L.).

Accepted for publication August 9, 2012

Address reprint requests to Frederick Schatz, Ph.D., Department of Obstetrics \& Gynecology, Ohio State University College of Medicine, Biomedical Research Tower, Room 836, 460 West 12th Ave., Columbus, $\mathrm{OH}$ 43210. E-mail: Frederick.Schatz@osumc.edu. 
trigger the clotting cascade. ${ }^{10}$ During human pregnancy, decidual cell (DC)-expressed TF prevents hemorrhage, initially as blastocyst-derived endovascular trophoblasts breach decidual capillaries, ${ }^{11}$ subsequently during placentation as endovascular trophoblasts mediate decidual arterial remodeling, ${ }^{12}$ and finally during the third stage of labor to prevent puerperal hemorrhage. ${ }^{13}$

In human term decidua, immunoreactive TF levels are highest in DCs, whereas adjacent interstitial trophoblasts (ITs) are virtually devoid of TF immunostaining. ${ }^{13}$ The thrombin-generating potential of decidual TF is reflected in the profound hypofibrinogenemia and disseminated intravascular coagulation accompanying severe placental abruption. ${ }^{14}$ The strong association between decidual TF-induced thrombin generation and prematurity is evident in the high predictive value of elevated circulating thrombin-antithrombin complex levels for subsequent occurrence of PPROM and PTD. ${ }^{15-17}$

Previous observations in our laboratory suggest that decidual thrombin generation plays a pivotal role in abruption-associated PPROM. Specifically, in vitro studies demonstrated that thrombin acts via proteaseactivated receptor (PAR-1) in cultured term DCs to induce mRNA and protein expression of matrix metalloproteinases 1 and 3 (MMP-1 and -3). ${ }^{18,19}$ Marked elevation in levels of both MMPs leads to degradation of the cellular matrix and is implicated in PPROM and cervical changes preceding labor. ${ }^{18-20}$ Thrombin markedly enhances IL-8 mRNA and protein levels in term DC cultures. ${ }^{21}$ We also observed that the decidua basalis of patients with abruption-induced PPROM in the absence of clinical evidence of infection contains a dense aseptic neutrophil infiltrate accompanied by elevated levels of interleukin-8 (IL-8), a potent neutrophil chemoattractant and activator. ${ }^{22}$ This abruption-associated increase in neutrophils colocalized with excess decidual fibrin deposits, as determined by picro-Mallory staining. ${ }^{21}$ These in situ observations are consistent with abruption-induced decidual generation of thrombin, which cleaves fibrinogen to fibrin.

Elevated P4 levels maintain myometrial quiescence during mammalian pregnancy. ${ }^{23}$ In most mammals, a decline in circulating P4 levels triggers parturition. In humans, however, as well as in some higher primates, placental P4 production and plasma P4 levels remain elevated until delivery. This phenomenon suggests that parturition is induced by functional P4 withdrawal, reflecting lower uterine progesterone receptor (PR) levels and/or a shift to dysfunctional PR isoform dominance. ${ }^{24}$ The clear involvement of excess DC-derived thrombin generation during abruption, taken together with our previous demonstration that term parturition is accompanied by reduced PR expression in DCs, ${ }^{25}$ led us to hypothesize that thrombin elicits functional P4 withdrawal during abruption-associated PTD. To address this issue, we sued a triple-immunostaining technique to assess PR expression in DCs and IT at the maternal-fetal interface in sections from abruption-associated, in comparison with gestational age-matched idiopathic PTD decidua basalis sections. This immunostaining included the glucocorticoid receptor (GR), be- cause competition between P4 and cortisol for the GR has been implicated in the onset of parturition. ${ }^{26} \mathrm{Com}$ plementing these in situ observations, the effects of thrombin on PR and GR mRNA and protein expression and PR activity were evaluated in primary cultures of leukocyte-free human term DCs.

Nuclear factor $\kappa \mathrm{B}$ p65 subunit (p65 NF- $\kappa \mathrm{B}$ ), p38 MAP kinase, and ERK $1 / 2$ are each a well-described intracelIular signaling mediator of thrombin effects in other cell types. ${ }^{27,28}$ First identified as an enhancer binding protein for immunoglobulin $\kappa$ light chain gene expression in $\mathrm{B}$ cells, NF- $\kappa \mathrm{B}$ enhances the expression of several molecules that regulate immune responses, inflammation, cell division, and apoptosis. NF- $\kappa \mathrm{B}$ is present in an inactive form in the cytoplasm and is usually comprised of heterodimers of p50 and p65 subunits. ${ }^{29,30}$ Cytoplasmic $\mathrm{NF}-\kappa \mathrm{B}$ is associated with an inhibitory protein, $I_{\kappa} \mathrm{B} \alpha$. Appropriate stimulation induces phosphorylation-mediated disassociation of $1 \kappa \mathrm{B} \alpha$ from NF- $\kappa \mathrm{B}$. Subsequently, the $\mathrm{NF}-\kappa \mathrm{B}$ dimer translocates to the nucleus and binds to a specific DNA sequence to regulate transcription. ${ }^{29}$ Thrombin-increased $I_{\kappa} \mathrm{B} \alpha$ phosphorylation results in elevated NF- $\kappa$ B activity in several cell types. ${ }^{31,32}$ The MAPK superfamily consists of three well-characterized subfamilies, p38 MAPK, c-Jun N-terminal kinase (JNK) MAPK, and ERK1/2 MAPK. ${ }^{33}$ The p38 MAPK and c-Jun N-terminal kinase pathways are activated in response to stress, resulting in promotion of inflammation and programmed cell death. ${ }^{34,35}$ By comparison, ERK $1 / 2$ MAPK is activated by phosphorylation in response to mitogens and growth factors. After activation, p38, JNK, and ERK1/2 MAPKs are translocated from the cytoplasm to the nucleus. ${ }^{36}$ Recent studies have demonstrated that thrombin activates p38 MAPK and ERK1/2 MAPK by increasing their phosphorylation in several cell types. ${ }^{27,31,32,37,38}$ In the present study, with the goal of understanding the molecular mechanisms underlying these thrombin effects, in situ and in vitro observations were extended to assess the involvement of the ERK signaling pathway on thrombin-mediated PR expression in DCs.

\section{Materials and Methods}

\section{Patients and Tissues for Immunohistochemistry}

After written informed consent had been received, placental specimens containing decidua basalis were obtained from patients with abruption-related PTDs $(n=7)$. Patients with idiopathic PTD served as gestational agematched controls $(n=7)$. The gestational age for abruption-associated PTD specimens ( $34.5 \pm 5.8$ weeks, mean \pm SD; range, 22 to 39.6 weeks) did not differ significantly from that for control patients ( $34.9 \pm 5.6$ weeks; range, 22 to 39.6 weeks). Cases displayed clinical and histological evidence of abruption, including recurrent vaginal bleeding and evidence of fresh clot formation on the placental bed and/or decidual hemosiderin deposition or retrochorionic hematoma formation. None of the control patients showed clinical evidence of abruption (ie, vaginal bleeding, hypofibrinogenemia, decidual hemosiderin, or retro- 
chorionic clot formation) and none displayed evidence of fever or histological chorioamnionitis (ie, $>10$ neutrophils per high-power field in the subchorionic space, chorion, or placental plate based on established criteria ${ }^{39}$ ). Both case and control patients were also without clinical evidence of clinical chorioamnionitis [ie, maternal fever $\left(>37.8^{\circ} \mathrm{C}\right)$, uterine tenderness, foul-smelling amniotic fluid or visualization of pus at the time of the speculum examination, maternal tachycardia ( $\geq 100$ beats/minute), or fetal tachycardia ( $\geq 160$ beats/minute).$^{40}$ All procedures were performed at Yale-New Haven Hospital and were approved by the Yale Human Investigation Committee $(\mathrm{HIC})$.

\section{Patients and Tissues for DC Cultures}

After written informed consent had been received, placentas and attached fetal membranes were obtained under HIC approval from patients $(n=8)$ with uncomplicated pregnancies undergoing repeat cesarean deliveries at term at Yale-New Haven Hospital. None of the specimens was obtained from patients in labor (ie, $>4$ contractions per hour, associated with cervical change). The decidua was separated from the amniochorion, and a small portion of the decidua was formalin-fixed and paraffin-embedded and then examined histologically for signs of underlying acute and chronic inflammation. The remainder of each specimen was used to isolate DCs.

\section{Immunohistochemistry}

Triple immunostaining was performed to detect either PR or GR together with vimentin and cytokeratin; single immunostaining was performed to detect total ERK $1 / 2$ or phosphorylated ERK1/2 (p-ERK1/2). Formalin-fixed, paraffin-embedded sections (5 $\mu \mathrm{m}$ thick) were deparaffinized in xylene and rehydrated through a descending ethanol series. Antigen retrieval involved boiling the slides in citrate buffer followed by endogenous peroxidase quenching with $3 \%$ hydrogen peroxide and blocking with $10 \%$ donkey or goat serum (Jackson ImmunoResearch, West Grove, PA). Serial sections were incubated overnight at $4^{\circ} \mathrm{C}$ with mouse monoclonal antibodies (mAbs) against PR (Dako, Carpinteria, CA) or against GR (R\&D Systems, Minneapolis, MN), or with rabbit polyclonal antibodies (pAbs) against total ERK1/2 (Biosource; Life Technologies, Carlsbad, CA) or p-ERK1/2 (pTpY185/187) (Biosource; Life Technologies). After a wash, slides were incubated with the appropriate biotinylated secondary antibodies (Vector Laboratories, Burlingame, CA) and then with a streptavidin-peroxidase complex (Elite ABC kit; Vector Laboratories). After a wash, diaminobenzidine tetrahydrochloride dehydrate (DAB; Vector Laboratories) was used to generate a brown stain for anti-PR, anti-GR, anti-total ERK1/2, and anti-p-ERK1/2 MAPK antibodies.

Triple-immunostained sections were incubated overnight with a chicken anti-vimentin pAb (Abcam, Cambridge, MA), then with a secondary antibody (donkey biotinylated anti-chicken IgG; Jackson ImmunoResearch), and then with a streptavidin-alkaline phospha- tase complex (Elite ABC kit; Vector Laboratories) for 30 minutes, and immunostaining was developed using the Vector Red (Vector Laboratories) for 30 minutes. These steps were repeated for cytokeratin staining using rabbit anti-cytokeratin pAb (Abcam), a donkey biotinylated antirabbit IgG (Jackson ImmunoResearch), and a streptavidinperoxidase complex (Elite ABC kit) and Vector SG (Vector Laboratories). For negative controls, appropriate nonspecific mouse IgG isotypes were used at the same concentrations as the primary antibodies. Slides were mounted and evaluated by histological scoring as described below (HSCORE Analysis).

Primary DCs grown in Falcon chamber slides (BD Biosciences, Bedford, MA) were subjected to immunofluorescence staining, using a similar protocol as described above, up to and including the normal goat serum blocking stage. After separate overnight incubation with each of the primary antibodies for PR or p-ERK $1 / 2$ or total ERK 1/2 MAPK, the slides were washed three times in PBS-Tween 20 and then incubated with goat AlexaFluor 568-labeled anti-mouse IgG or anti-rabbit IgG for 30 minutes. After a wash, the slides were mounted using Vectashield mounting medium with DAPI (Vector Laboratories).

\section{HSCORE Analysis}

The intensity of immunostaining for PR, GR, total ERK $1 / 2$, and $\mathrm{p}$-ERK $1 / 2$ was semiquantitatively evaluated using histological score (HSCORE) analysis and scored as follows: 0 , no staining; 1 , weak, but detectable, staining; 2 , moderate staining; and 3 , intense staining. For each tissue, an HSCORE value was derived by summing the percentages of cells that stained at each intensity category and multiplying that value by the weighted intensity of the staining, using the formula

$$
\text { HSCORE }=\sum_{i} i \times P_{i},
$$

where $i$ represents the intensity scores, and $P_{i}$ is the corresponding percentage of the cells. In each slide, five randomly selected areas were evaluated under a light microscope at $\times 40$ magnification. ${ }^{25,41}$ The HSCORES were determined at different times by two independent observers (U.A.K. and W.M.) masked to tissue type and clinical outcome, and the average score of both observers was then used as the final HSCORE for each sample. The intra- and interindividual coefficients of variation were $10 \%$ and $13 \%$, respectively.

\section{Experimental Cell Incubations}

DCs were isolated as described previously. ${ }^{42}$ Isolated decidual cells $\left(5 \times 10^{5}\right.$ cells $\left./ \mathrm{mL}\right)$ were suspended in basal medium, a Phenol Red-free 1:1 v/v mix of Dulbecco's modified Eagle's medium (Invitrogen; Life Technologies, Carlsbad, CA) and Ham's F-12 (Flow Laboratories, Inglewood, CA) with $100 \mathrm{U} / \mathrm{mL}$ penicillin, $100 \mu \mathrm{g} / \mathrm{mL}$ streptomycin, and $0.25 \mu \mathrm{g} / \mathrm{mL}$ amphotericin B (Fungizone) supplemented with $10 \%$ charcoal-stripped calf serum. Confluent leukocyte-free DCs were primed for 7 days in basal medium with charcoal-stripped calf serum 
Table 1. Primer Sequences Used in Quantitative Real-Time PCR

\begin{tabular}{lccc}
\hline \multicolumn{1}{c}{ Gene } & Sense & Antisense & Size (bp) \\
\hline ACTB $(\beta$-actin $)$ & 5'-CGTACCACTGGCATCGTGAT-3' & $5^{\prime}$-GTGTTGGCGTACAGGTCTTTG-3' \\
$P R$ & 5'-AGCCCTAAGCCAGAGATTCA-3' & $5^{\prime}$-TAGGATCTCCATCCTAGACC-3' & 452 \\
GR & 5'-CCTAAGGACGGTCTGAAGAGC-3' & $5^{\prime}$ GCCAAGTCTTGGCCCTCTAT-3' & 303 \\
\hline
\end{tabular}

containing either vehicle control ( $0.1 \%$ ethanol), or $10^{-8}$ $\mathrm{mol} / \mathrm{L}$ of estradiol (E2), or $10^{-7} \mathrm{~mol} / \mathrm{L}$ of medroxyprogesterone acetate (MPA) (Sigma-Aldrich, St. Louis, MO) or E2+MPA with one change of medium. The cultures were washed twice with PBS and switched to a serum-free defined medium (DM) consisting of basal medium with ITS+ Premix culture supplement (BD Biosciences, Bedford, MA), $5 \mu \mathrm{mol} / \mathrm{L} \mathrm{FeSO}_{4}, 0.5 \mu \mathrm{mol} / \mathrm{L} \mathrm{ZnSO}_{4}, 1 \mathrm{nmol} / \mathrm{L}$ $\mathrm{CuSO}_{4}, 20 \mathrm{nmol} / \mathrm{L} \mathrm{Na}_{2} \mathrm{SeO}_{3}$, trace elements (Life Technologies), $50 \mu \mathrm{g} / \mathrm{mL}$ ascorbic acid (Sigma-Aldrich), and $50 \mathrm{ng} / \mathrm{mL}$ epidermal growth factor (BD Biosciences) with either vehicle or steroids with or without thrombin (American Diagnostic, Greenwich, CT) for 24 hours. A subset of cultures was incubated with the specific inhibitors PD98059 (PD, an ERK1/2 MAPK inhibitor), SB203580 (a p38 MAPK inhibitor), or NF- $\kappa \mathrm{B}$ activation inhibitor III (NF-kB III) (Calbiochem-EMD; Millipore, San Diego, CA) for test periods of 15 minutes (short term) and 24 hours (long term).

After the various test periods, the cells were rinsed in ice-cold PBS, stored in the dishes at $-80^{\circ} \mathrm{C}$ for several days, and then lysed with a protease inhibitor cocktail kit and extraction kit (NE-PER; Thermo Scientific, Rockford, IL) to extract nuclear and cellular proteins. Conditioned DM supernatants and cell lysates were stored at $-80^{\circ} \mathrm{C}$. Parallel incubations after a 6-hour test period were used to extract RNA.

\section{Western Blotting}

Western blot analysis was performed on nuclear extracts (50 $\mu \mathrm{g} / \mathrm{lane}$ from DCs and $8 \mu \mathrm{g} / \mathrm{lane}$ from T47D cells, a positive control for PR and GR; Abcam), which were subjected to reducing SDS-PAGE on a 7.5\% Tris-HCl gel (Bio-Rad, Hercules, CA). Transfer onto nitrocellulose, blocking, washing, chemiluminescence, and stripping were performed as described previously. ${ }^{13}$ Immunoblotting used an mAb specific for PR-A and PR-B (Dako) and then incubation with horseradish peroxidase-conjugated goat anti-mouse IgG (ICN Biomedicals, Aurora, OH). Signals were developed using a chemiluminescence kit (Amersham; GE Healthcare, Piscataway, NJ). The membrane was sequentially stripped and reprobed with mAbs for GR (R\&D Systems), and then for TATA-binding protein (Abcam) for the loading control.

After short-term (15 minutes) incubations of DCs with thrombin, with and without specific intracellular signaling inhibitors, cells were lysed in $1 \times$ SDS sample buffer $(100 \mu \mathrm{L} /$ well in a six-well plate) for total protein extraction and subjected to SDS-PAGE electrophoresis. Immunoblotting initially used a rabbit pAb specific for p-ERK 1/2 (pTpY185/187; Biosource; Life Technologies), a rabbit pAb specific for p-p65 NF-кB (S276;
Cell Signaling Technology, Danvers, MA), or a rabbit mAb specific for p-p38 MAPK (T180/Y182; Cell Signaling Technology). Membranes were then incubated with HRP-conjugated goat anti-rabbit IgG (Vector Laboratories). Signals were developed using a chemiluminescence kit (Amersham; GE Healthcare). Membranes were sequentially stripped and reprobed with a pAb for total ERK1/2 (Biosource; Life Technologies), a rabbit mAb for total p65 NF-кB (C22B4; Cell Signaling Technology), a rabbit pAb for total p38 MAPK (Cell Signaling Technology), and finally a mAb for $\beta$-actin (Abcam) used as a loading control.

\section{Quantitative Real-Time RT-PCR}

Total RNA was extracted with TRI reagent (Sigma-Aldrich) according to the manufacturer's instructions. To obtain cDNAs, reverse transcription was performed with $1 \mu \mathrm{g}$ of total RNA and a kit using SuperScript II Reverse Transcriptase (Invitrogen; Life Technologies) in an Eppendorf master cycler (Eppendorf, Westbury, NY). A quantitative standard curve was created using serial dilutions of cDNA. Real-time quantification of PR, GR, and $\beta$-actin was determined using SYBR Green master mix and a LightCycler system (Roche Diagnostics, Indianapolis, IN). Melting curve analysis determined the specificity of the amplified products and the absence of primerdimer formation. The primers were synthesized and gelpurified at the Yale DNA Synthesis Laboratory, Critical Technologies Program (Table 1).

\section{Electrophoretic Mobility Shift Assay}

For electrophoretic mobility shift assay (EMSA), the DCs were homogenized in solution A (10 mmol/L HEPES-KOH $\mathrm{pH} 7.9,10 \mathrm{mmol} / \mathrm{L} \mathrm{KCl}, 1.5 \mathrm{mmol} / \mathrm{L} \mathrm{MgCl} 2,0.1 \mathrm{mmol} / \mathrm{L}$ EGTA, $0.5 \mathrm{mmol} / \mathrm{L}$ phenylmethylsulfonyl fluoride, and 0.5 $\mathrm{mmol} / \mathrm{L}$ dithiothreitol) (Bio-Rad). Nuclei were pelleted at $4^{\circ} \mathrm{C}$, resuspended in solution B (solution A with 420 $\mathrm{mmol} / \mathrm{L} \mathrm{NaCl}, 5 \% \mathrm{v} / \mathrm{v}$ glycerol; Fisher Scientific, Pittsburgh, PA), rocked for 30 minutes at $4^{\circ} \mathrm{C}$, and then centrifuged at $14,000 \times g$ at $4^{\circ} \mathrm{C}$ for 20 minutes. Supernatant aliquots were stored at $-80^{\circ} \mathrm{C}$. Double-stranded DNA probes with a consensus PR binding site (5'-GATCCTGTACAGGATGTTCTAGCTACA-3') were end-labeled with ${ }^{32} \mathrm{P}$ and incubated with $5 \mu \mathrm{g}$ of nuclear proteins for 30 minutes at $25^{\circ} \mathrm{C}$ with $0.05 \mu \mathrm{g} / \mu \mathrm{L}$ of salmon sperm DNA (Sigma-Aldrich). Binding specificity was tested in the presence of 100-fold excess of unlabeled wild-type probes or unlabeled probes containing a mutation on the PR binding site. Samples were loaded onto a $6 \%$ polyacrylamide nondenaturing gel and electrophoresed in $0.5 \times$ Tris-borate-EDTA buffer at $4^{\circ} \mathrm{C}$ for 90 minutes. Au- 


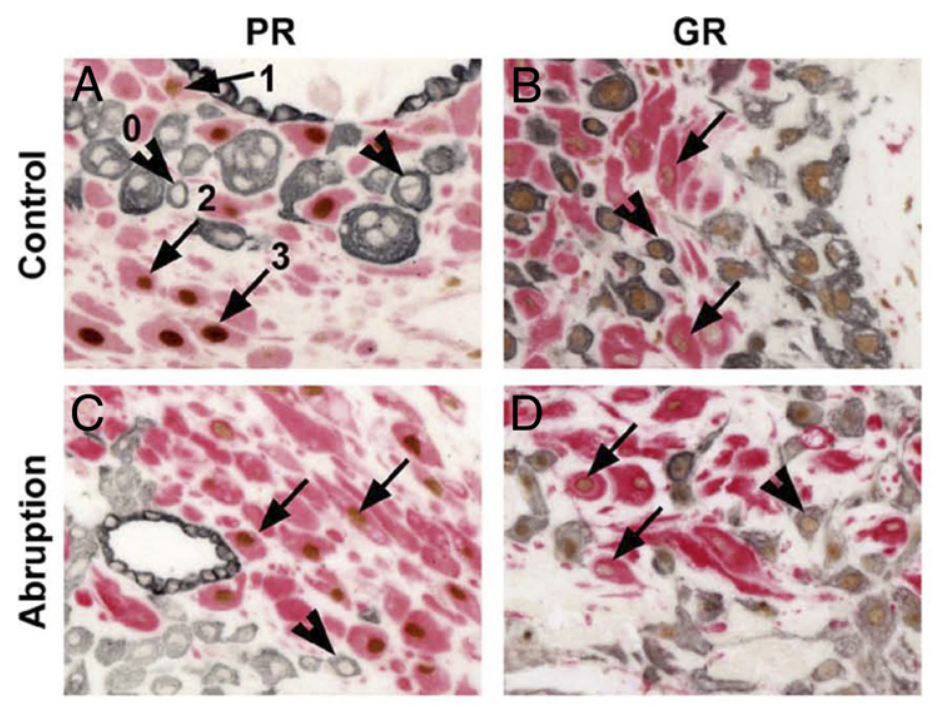

\section{$\mathrm{E}$}

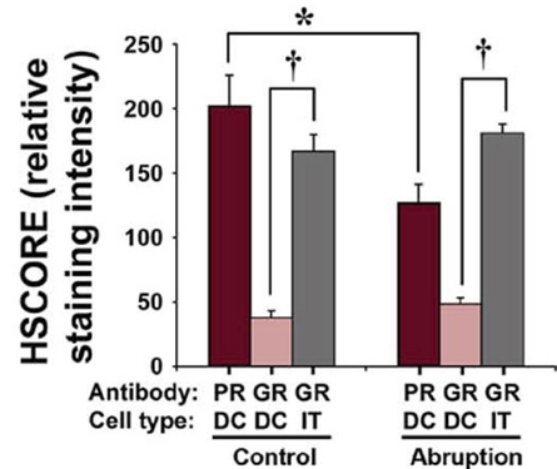

Figure 1. Immunoreactive PR and GR in DCs (arrows) and ITs (arrowheads) of control and abruption-complicated decidua, with HSCORE staining intensity analysis. A-D: Tissues were triple-stained for vimentin (red) to identify DCs, cytokeratin (gray) to identify ITs, and brown to identify either PR or GR. PR was localized to DCs, with significantly lower staining in abruption-complicated versus control specimens. GR staining in DCs was low, with no differences between abruption-complicated and control specimens. In both control and abruption specimens, GR immunostaining was significantly higher in intensity in ITs than in DCs. Numbers in A mark representative examples of staining intensity in cell nuclei : 0, absent; 1, weak; 2, moderate; and 3, intense staining. E: HSCOREs for $\mathrm{PR}$ and GR by cell type (DC versus IT). Data are expressed as means \pm SEM. ${ }^{*} P<0.05$, PR in control versus abruption; ${ }^{\dagger} P<0.05$, GR in DCs versus ITs. $n=$ 7 different patient tissue samples for each group.

toradiography of the dried gels identified free and bound probes.

\section{PR Binding Assay}

After incubation of DC nuclear proteins at $4^{\circ} \mathrm{C}$ for 16 hours in $0.5 \mathrm{~mL}$ TEMGD buffer consisting of $10 \mathrm{mmol} / \mathrm{L}$ Tris- $\mathrm{HCl}, \mathrm{pH} 7.4,1.5 \mathrm{mmol} / \mathrm{L}$ EDTA, 10\% glycerol, 25 $\mathrm{mmol} / \mathrm{L}$ sodium molybdate, $1 \mathrm{mmol} / \mathrm{L}$ dithiothreitol, and 5 $\mathrm{nmol} / \mathrm{L}\left[{ }^{3} \mathrm{H}\right] \mathrm{P} 4$ (NEN; PerkinElmer, Waltham, MA), bound and free tracers were separated by adding $0.1 \mathrm{~mL}$ icecold, vigorously stirred, dextran-coated charcoal (25 g Norit A activated charcoal, 250 to 350 mesh; SigmaAldrich) and $2.5 \mathrm{~g}$ dextran (Sigma-Aldrich) in $100 \mathrm{~mL}$ of TEMGD buffer (Sigma-Aldrich). Centrifugation at $3000 \times$ $g$ for 10 minutes at $4^{\circ} \mathrm{C}$ was followed by liquid scintillation counting of supernatants (LS 6000SC; Beckman Coulter, Brea, CA). Nonspecific binding was measured in the presence of $5 \mu \mathrm{mol} / \mathrm{L}$ of unlabeled P4; specific binding is expressed in counts per minute (cpm/ng protein).

\section{Statistical Analysis}

Immunostaining HSCOREs for PR and GR and the EMSA PR/DNA-binding results were normally distributed, and the results were analyzed by one-way analysis of variance with post hoc Holm-Šidák test for HSCOREs and post hoc Tukey test for EMSA data. Quantitative RT-PCR results were not normally distributed, and therefore pairwise multiple comparisons were analyzed with the Kruskal-Wallis test analysis of variance, followed by the post hoc Student-Newman-Keuls test. The PR binding assay results and immunostaining HSCOREs for total and p-ERK1/2 MAPK were analyzed using a t-test. Control and treatment groups were compared, with $P<0.05$ representing statistical significance. Statistical calculations used SigmaStat version 3.0 (Systat Software, San Jose, CA).

\section{Results}

Representative immunostaining for $\mathrm{PR}$, using an antibody that recognizes both $P R-A$ and $P R-B$, and for GR in abruption-complicated and gestational age-matched control decidual sections are shown in Figure 1. The tissues were also consecutively stained with the DC marker vimentin and the trophoblast marker cytokeratin, to localize the cell type expressing PR and GR. Immunoreactive PR was localized exclusively in DC nuclei in both cases and controls. Significantly lower PR staining intensity was found in abruption-complicated decidua, compared with controls (Figure 1, A and C). The PR HSCORE differed significantly between abruption and controls $(P<0.05)$ (Figure 1E). Immunostaining for GR, however, was preferentially localized to ITs in both cases and controls, with weak staining evident in DCs (Figure 1, B and D). The GR HSCORE differed significantly between ITs and DCs $(P<$ 0.05 ) (Figure 1E). No differences in the intensity of GR immunostaining were noted between abruption and control specimens in either ITs or DCs (Figure 1, B and D). Negative controls for both PR and GR showed no staining (data not shown).

The reduced abruption-related immunostaining for PR prompted examination of thrombin effects on steadystate PR mRNA levels in leukocyte-free term DC cultures. Thrombin and MPA each significantly lowered PR mRNA levels, compared with E2 alone (Figure 2). Inhibition was greatest in cultures coincubated with both MPA and thrombin. In contrast, neither MPA nor thrombin significantly affected GR mRNA expression, whether added 

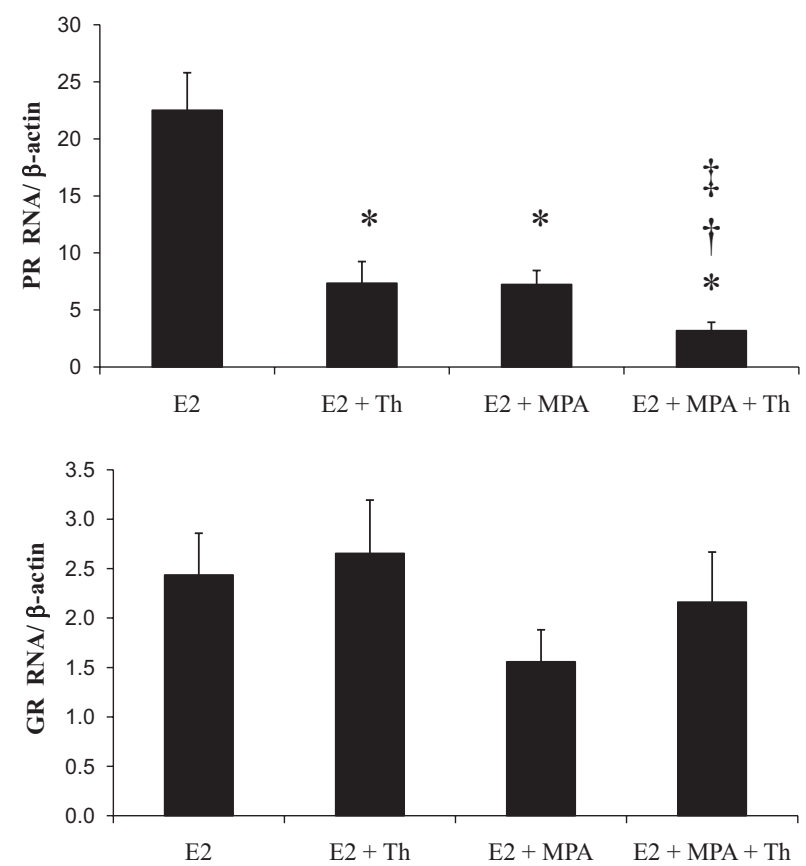

Figure 2. Thrombin effects on PR and GR mRNA levels in DCs. Term DCs were primed in E2 or E2+MPA, then switched to DM with corresponding steroids $\pm 2.5 \mathrm{U} / \mathrm{mL}$ thrombin (Th) for 6 hours, as described under Materials and Methods. RNA was measured by quantitative real-time RT-PCR, for PR and GR. Values were normalized to $\beta$-actin mRNA. Data are expressed as means \pm SEM. ${ }^{*} P<0.05$ versus E2; ${ }^{\dagger} P<0.05$ versus $\mathrm{E} 2+\mathrm{Th} ;{ }^{\ddagger} P<0.05$ versus E2+MPA. $n=8$.

separately or together. Similarly, Western blotting of nuclear extracts indicated that primary term DCs expressed PR-B bands (116 kDa) and PR-A bands (82 kDa), with both isoforms greatly enhanced by E2 and to a lesser extent by MPA alone (Figure 3). Addition of thrombin with both E2 and MPA markedly reduced both PR isoform levels; concentration dependence of thrombin inhibition was clearly evident in coincubations with E2. Unlike the inhibition of PR expression by thrombin and MPA, a band migrating with the mobility of GR ( $94 \mathrm{kDa}$ ) was unaltered by incubation with the steroids or thrombin added separately or in combination.

The binding activity of nuclear extracts of term DCs to DNA probes containing a consensus PR binding site is shown in Figure 4. Thrombin elicited a concentrationdependent inhibition of PR in this DNA binding activity that attained statistical significance at $2.5 \mathrm{U} / \mathrm{mL}$. The specificity of DNA binding activity is shown in Figure 5. Basal binding activity was eliminated by including excess unlabeled (cold) wild-type probe in the reaction, whereas binding activity was unaffected by adding a similar excess of a probe containing a mutated PR binding site. In E2+MPA-treated term DCs, $2.5 \mathrm{U} / \mathrm{mL}$ of thrombin significantly decreased nuclear extract specific [ $\left.{ }^{3} \mathrm{H}\right] \mathrm{PR}$ binding activity, as determined by a standard steroid receptor binding assay (Figure 6).

During parallel incubations with E2 or with E2+MPA, used to mimic the steroid milieu of pregnancy, term decidual monolayers expressed both phosphorylated and total forms of p65 NF- $\kappa$ B, p38 MAP kinase, and ERK1/2 (Figure 7A). However, during coincubation of E2+MPA

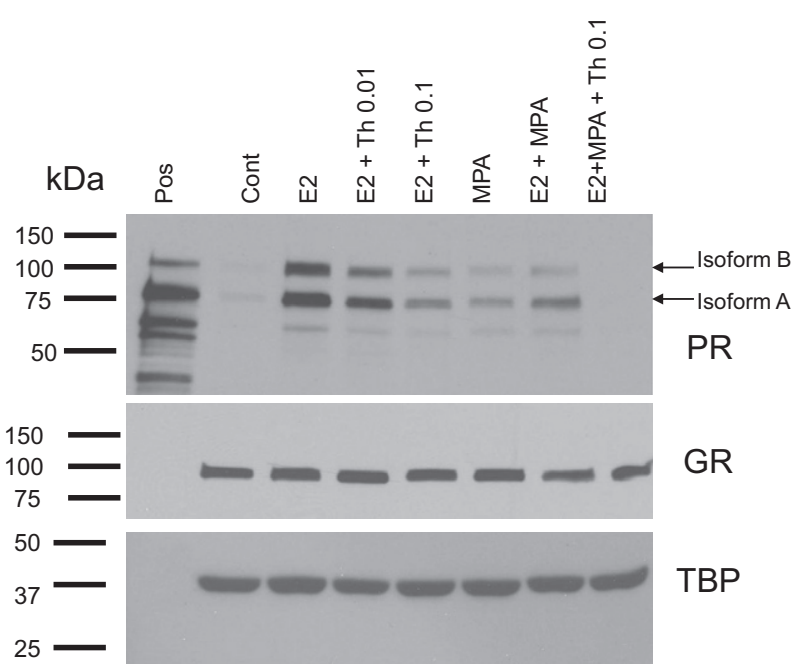

Figure 3. Representative Western blot of term DCs, displaying effects of thrombin, E2, and MPA on levels of immunoreactive PR and GR. Confluent leukocyte-free DCs were primed for 7 days with vehicle (Control), or $10^{-8}$ $\mathrm{mol} / \mathrm{L} \mathrm{E} 2$, or $10^{-7} \mathrm{~mol} / \mathrm{L}$ MPA or both. Primed DCs were incubated for 24 hours with the corresponding steroids or control with or without 0.1 or 0.01 $\mathrm{U} / \mathrm{mL}$ thrombin (Th) for 24 hours in DM, as described under Materials and Methods. Nuclear extracts $(50 \mu \mathrm{g}$ per lane) were subjected to reducing SDS-PAGE. Western blotting was performed for PR, then stripped and reprobed consecutively for GR and then for the loading control, TBP. The positive control (Pos) for PR was $8 \mu \mathrm{g}$ of T47D nuclear extracts.

with thrombin, levels of p-ERK1/2 (but not of p-p38 MAPK or p-p65 NF- $\mathrm{B}$ ) appear to be elevated, compared with the respective nonphosphorylated form. Moreover, in coincubations of E2+MPA, the addition of a specific inhibitor for either NF- $\kappa \mathrm{B}$ activation (NF- $\kappa \mathrm{B}$ III) or p38 MAPK activation (SB203580) not only failed to reverse thrombinmediated inhibition of PR-A and PR-B expression, but lowered levels of both PR isoforms further (Figure 7B). Densitometry confirmed that only $\mathrm{p}-\mathrm{ERK} 1 / 2$ was clearly up-regulated by thrombin (Figure 7).

Western blotting revealed the effects of PD (an ERK1/2 MAPK action inhibitor) in reversing thrombin inhibition of PR-A and PR-B expression (Figure 8, A and C) and blunting thrombin induction of phosphorylated but not total ERK1/2 (Figure 8, B and D) in term DC monolayers. Compared with E2 alone, PR-A and PR-B levels were
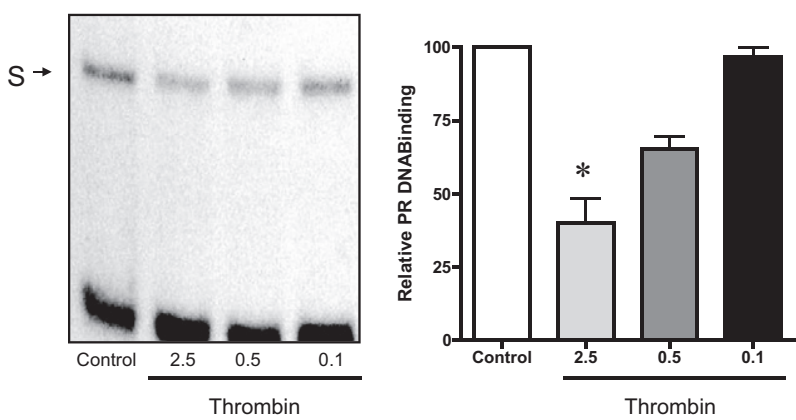

Figure 4. DNA binding activity of PRs in nuclear extracts from control versus thrombin-treated term DCs reveals concentration-dependent thrombin effects. Confluent term DCs were incubated with and without thrombin $(\mathrm{U} / \mathrm{mL})$ for 24 hours. EMSAs (left) were performed on nuclear extracts (see Materials and Methods). One representative EMSA is shown (left), with densitometry results (right). $\mathbf{S}$ indicates band shift. Data are expressed as means \pm SEM. ${ }^{*} P<0.05$ versus control, analysis of variance with Tukey post hoc test. $n=3$ 


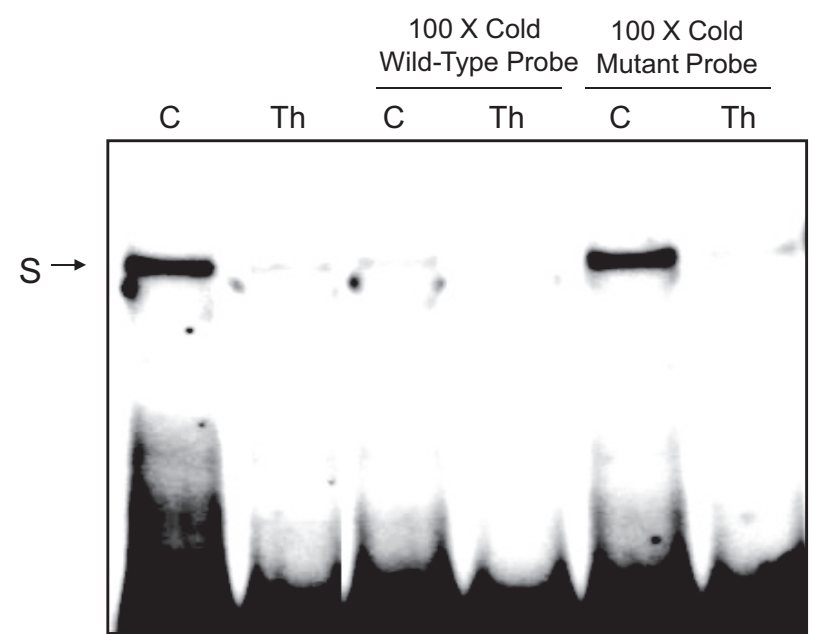

Figure 5. Specificity of DNA binding activity of PRs in nuclear extracts from control versus Th term DCs. Excess wild-type probe without radiolabel (100× cold) in the reaction eliminated basal binding activity, but similar excess of cold probe containing a mutated PR binding site had no effect. Confluent term DCs were incubated with and without thrombin $(2.5 \mathrm{U} / \mathrm{mL})$ for 24 hours. Electrophoretic mobility shift assays were performed on nuclear extracts, as described under Materials and Methods. $\mathbf{S}$ indicates band shift.

lowered in parallel incubation with E2+MPA and lowered further by thrombin; the latter effect was reversed during coincubation with PD (Figure 8A). Compared with E2 alone, E2+MPA modestly inhibited phosphorylated but not total ERK1/2 (Figure 8B). Cultures incubated with E2+MPA and thrombin displayed clear up-regulation of phosphorylated but not total ERK1/2, an effect blocked by PD. Parallel incubations were performed with E2 alone, to increase the sensitivity of detecting thrombin

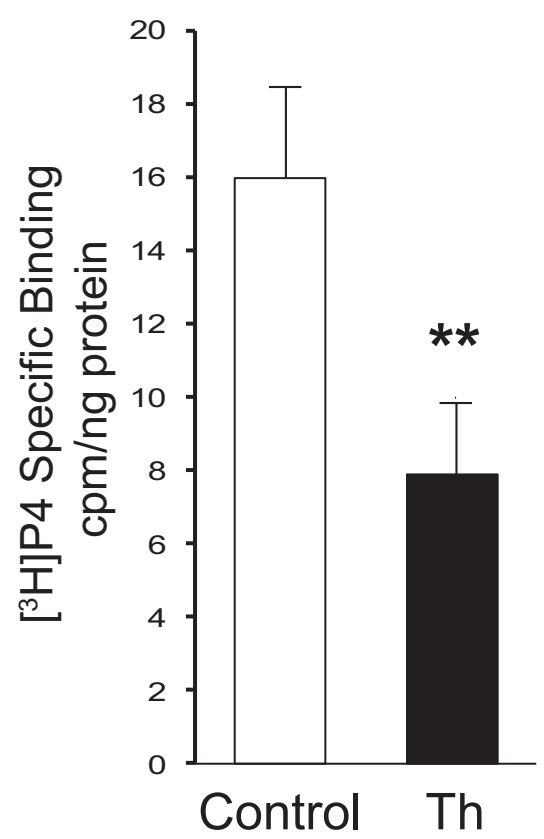

Figure 6. Effect of thrombin on $\mathrm{P} 4$ receptor binding activity in term DCs. Confluent term DCs were incubated with Th $(2.5 \mathrm{U} / \mathrm{mL})$ or without (Control) for 24 hours. Nuclear extracts were analyzed with a steroid receptor binding assay. Data are expressed as means \pm SEM. ${ }^{* * *} P<0.01$ Student's $t$-test. $n=5$.
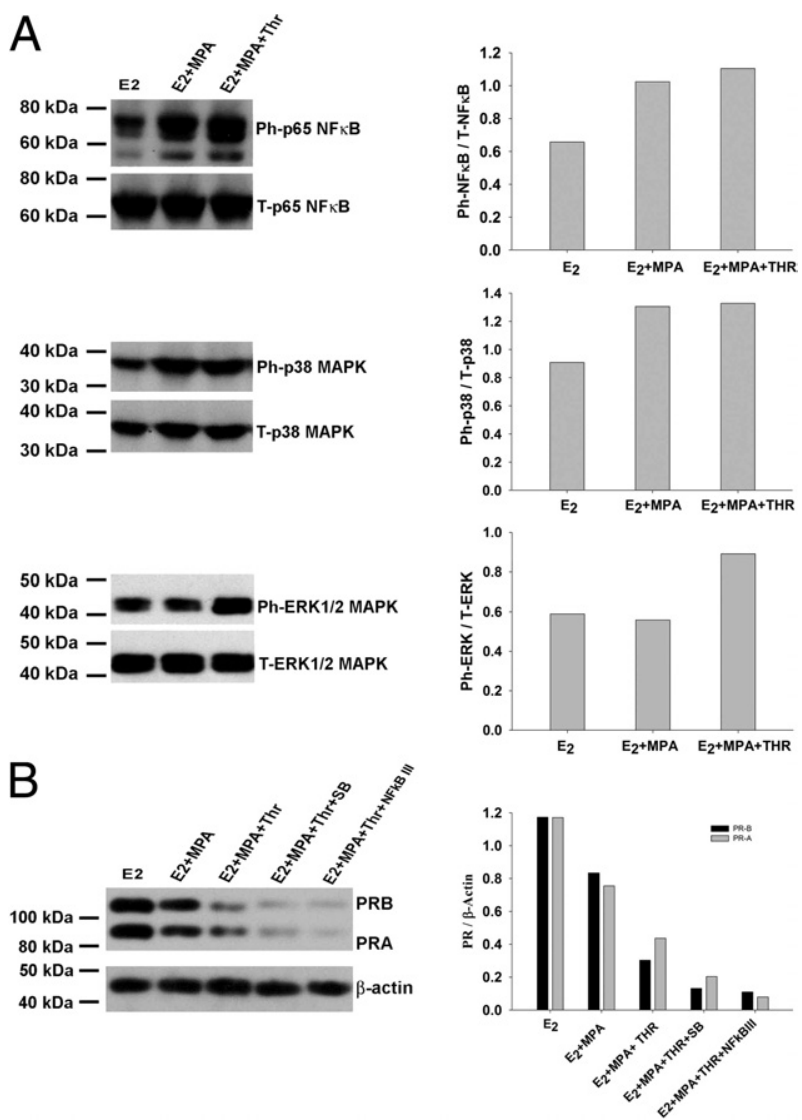

Figure 7. Western blot of term DCs showing effects of Thr on activation of intracellular signaling molecules. A: Confluent leukocyte-free DCs, primed for 7 days with E2, or E2+MPA, were incubated with E2, or E2+MPA, or $\mathrm{E} 2+\mathrm{MPA}+\mathrm{Thr}(1 \mathrm{U} / \mathrm{mL})$ in DM for 15 minutes. Specific antibodies detected phosphorylated and total p $65 \mathrm{NF}-\kappa \mathrm{B}$, phosphorylated and total p38 MAPK, and phosphorylated and total ERK1/2 MAPK. B: PR levels in cultured term DCs incubated for 24 hours with E2, or E2+MPA, or E2+MPA+Thr $(1 \mathrm{U} / \mathrm{mL})$ with or without NF- $\kappa$ B activation inhibitor III (NF- $\kappa$ B III $; 10^{-6} \mathrm{~mol} / \mathrm{L}$ ) or with or without the p38 MAPK inhibitor SB203580 (SB; $10^{-6} \mathrm{~mol} / \mathrm{L}$ ). Densitometry data derived from arbitrary densitometric readings, using Image software version $1.45 \mathrm{~s}$ (NIH, Bethesda, MD), indicated that, in parallel incubations with E2+MPA, only p-ERK1/2 was increased during coincubation with thrombin (A), and that coincubation with specific inhibitors of NF- $\kappa$ B activation (NF- $\kappa$ B III) or p38 MAPK activation (SB203580) further lowered levels of both PR-A and PR-B (B). Ph-, phosphorylated; T-, total.

reciprocal effects on $\mathrm{PR}$ and $\mathrm{p}$-ERK1/2 expression (Figure 8, C and D). Thrombin inhibited PR-A and PR-B, and $\mathrm{PD}$ reversed this inhibition (Figure $8 \mathrm{C}$ ). Furthermore, thrombin increased expression of phosphorylated but not total ERK1/2, and the addition of PD reversed thrombinmediated up-regulation of $\mathrm{p}$-ERK1/2 (Figure 8D). Densitometry confirmed the Western blot results (Figure 8, C and D). Thus, compared with the $\beta$-actin loading control, thrombin lowered PR-A and PR-B levels and enhanced p-ERK1/2 versus total ERK1/2, whereas coincubation with $P D$ reversed both thrombin-inhibited PR expression and thrombin-augmented $\mathrm{p}$-ERK $1 / 2$ expression (Figure 8, C and D).

The Western blotting results (Figure 8) were confirmed by inspection of immunofluorescence staining of term DC monolayers (Figure 9). Specifically, the immunofluorescence data indicated that, in incubations with E2, addition of thrombin for 24 hours decreased both the staining intensity and the number of PR-positive cells, which was re- 

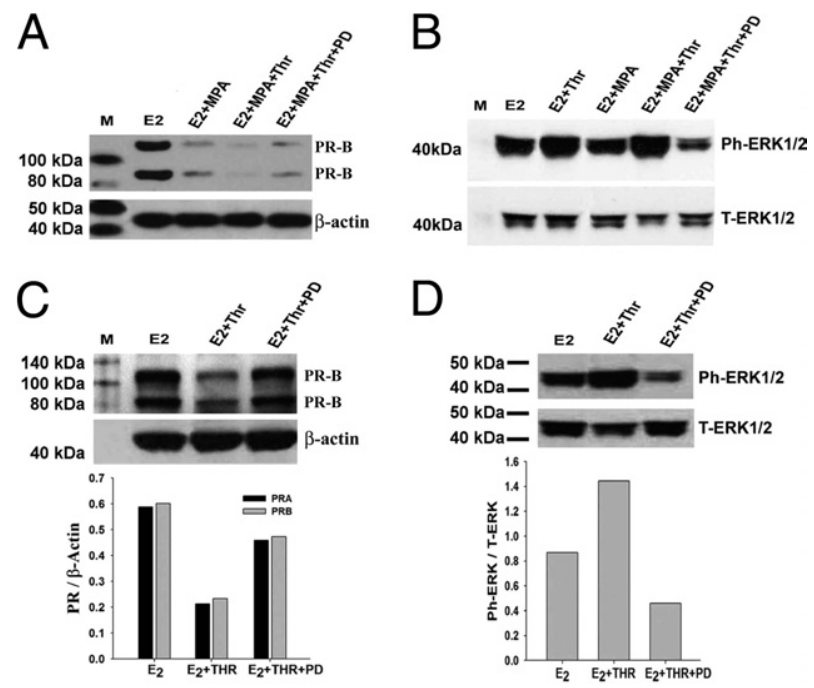

Figure 8. Western blotting of term DCs demonstrates thrombin-mediated effects on ERK1/2 signaling and inhibition of PR isoform expression. $\mathbf{A}$ and B: Confluent leukocyte-free term DCs were incubated with E2 alone or with MPA, MPA+Thr, or MPA+Thr+PD in DM for 24 hours (A) or with E2 alone or with Thr, MPA, MPA+Thr, or MPA+Thr+PD for 15 minutes (B). Thrombin concentration, $1 \mathrm{U} / \mathrm{mL}$; ERK1/2 inhibitor PD98059 (PD) concentration, $10^{-6}$ $\mathrm{mol} / \mathrm{L}$. C and D: Parallel incubations with thrombin with or without PD were performed in the presence of E2 but the absence of MPA for 24 hours (C) or 15 minutes (D). Densitometry data derived from arbitrary densitometric readings, using ImageJ software, indicated reversal of the effects of thrombin on PR expression (C) and ERK1/2 phosphorylation (D) during coincubation with PD (E2+THR+PD). M, molecular weight ladder.

versed by coincubation with PD (Figure 9A). Moreover, short-term (15 minutes) incubation with thrombin augmented p-ERK1/2, which again was reversed by PD (Figure 9B). In contrast, expression of total ERK $1 / 2$ was unaffected by either thrombin or PD (Figure 9C).

Immunostaining of decidual sections provided in situ evidence that, at the maternal-fetal interface, $p$-ERK1/2 is preferentially enhanced in the nuclei of DCs in abruption (Figure 10, C and D). By contrast, no such abruptionassociated changes were evident for total ERK1/2, which stained both nuclei and cytoplasm of DCs (Figure 10, A and B). Moreover, there were no abruption-related changes for either total ERK1/2 or p-ERK1/2 in ITs (Figure 10). These findings were confirmed by HSCORES indicating that DCs also display significantly increased p-ERK1/2 $(P<0.05)$, compared with ITs, in the decidua of abruption specimens (Figure 10E).

\section{Discussion}

The PRs belong to a superfamily of ligand-activated nuclear transcription factors comprised of specific domains that mediate DNA binding, hormone binding, and transactivation. ${ }^{43}$ In target tissues, progestin activation of PR involves dimerization, phosphorylation, and subsequent binding to cis-acting P4 response elements on DNA that modulate activity of target gene promoters. Both PR-A and PR-B display the same binding affinity for $\mathrm{P} 4$, and are encoded by a single gene under the control of separate estrogen-sensitive promoters that give rise to distinct mRNA species. ${ }^{44}$ Cotransfections with different reporter constructs in cell lines not normally expressing PR indi- cated that PR-B displays hormone-dependent transactivation, whereas PR-A displays cell-specific and reporterspecific activity that may be similar to PR-B, or may be inactive, or may behave as a transdominant PR-B inhibitor. ${ }^{45}$ Moreover, PR-A can affect the transcriptional activity of glucocorticoid, mineralocorticoid, androgen, and estrogen receptors. ${ }^{23}$

In most mammalian species, a rapid lowering of maternal P4 levels precedes labor. In humans, however, maternal, fetal, and amniotic fluid P4 levels remain elevated until delivery. This paradox has fostered the concept (reviewed by Thijssen ${ }^{23}$ ) that parturition is initiated by functional P4 withdrawal, reflecting reduced expression of PR levels and/or a shift in the ratio of PR isoforms that result in dominance of dysfunctional PR-A over functional PR-B. The onset of functional P4 withdrawal has been attributed to local mechanisms that block P4 inhibition of proparturition autocrine/paracrine effector molecules such as cyclooxygenase/prostaglandins, proinflammatory cytokines, gap junctions, and MMPs in the myometrium, cervix, fetal membranes, and/or decidua. ${ }^{46-48}$

A
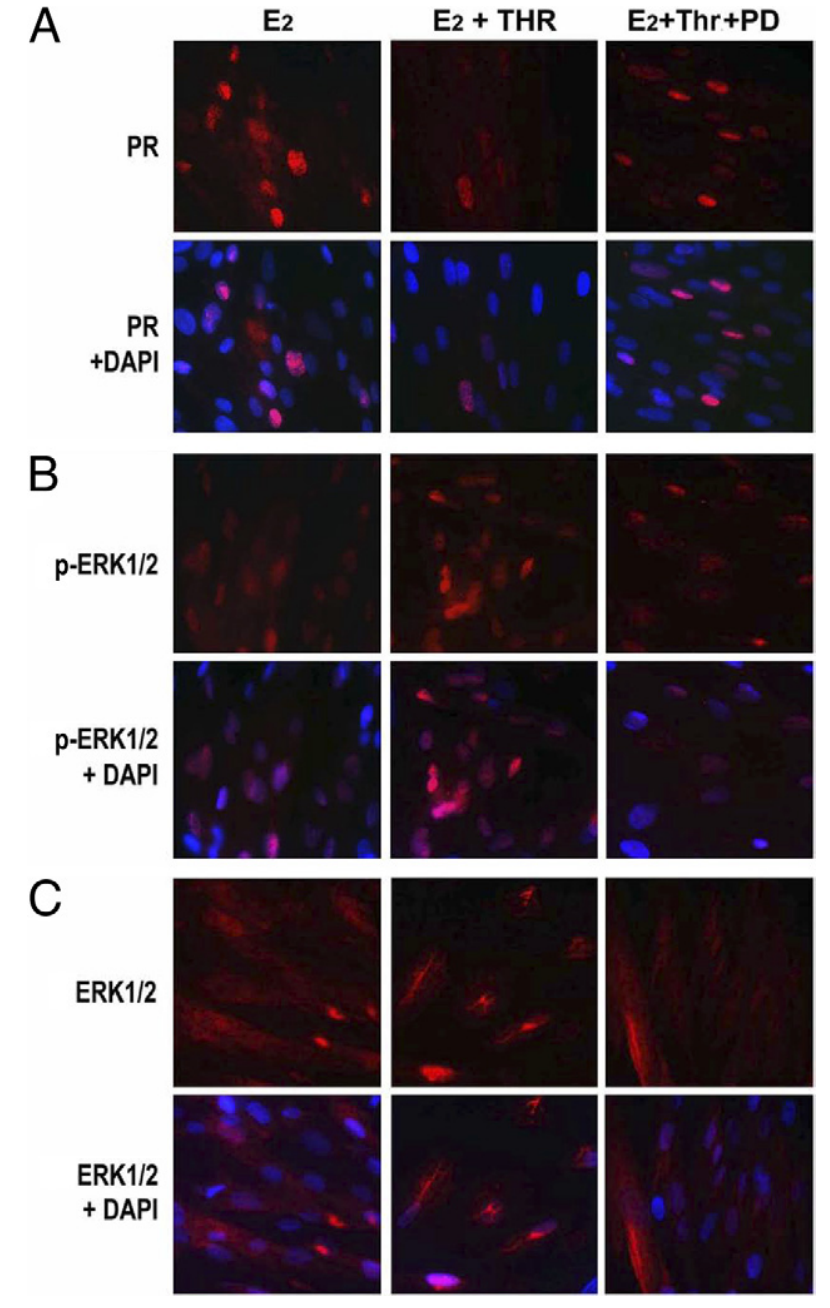

$\mathrm{E} 2+\mathrm{Thr}+\mathrm{PD}$

Figure 9. Immunofluorescence staining for thrombin-mediated-regulation of PR and ERK1/2 MAPK activity in cultured term DCs. Red fluorescence indicates PR (A), phosphorylated p-ERK1/2 (B), or total ERK1/2 (C) with or without PD. DAPI (blue) was used as a nuclear counterstain. 


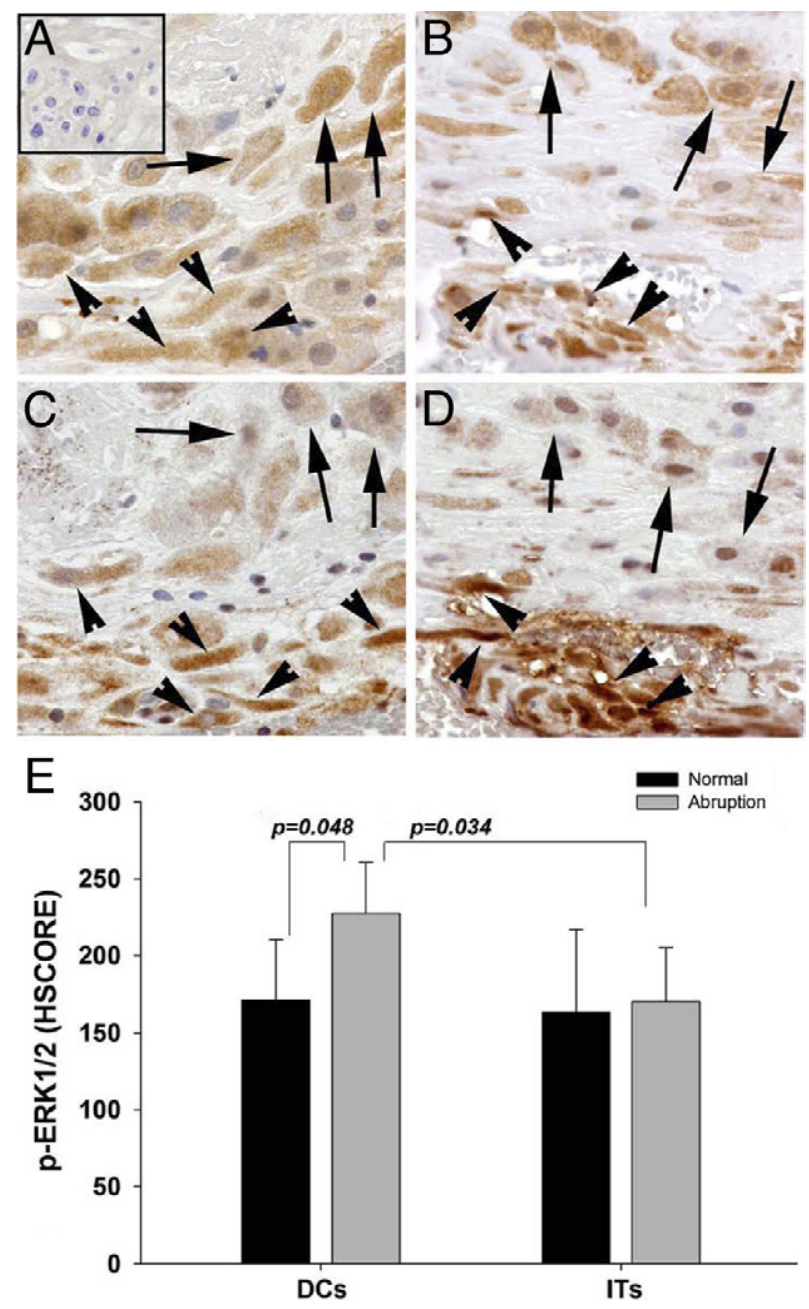

Figure 10. Expression of phosphorylated and total ERK1/2 MAPK in DCs and ITs in decidua of control and abruption-related specimens. Immunoreactive p-ERK1/2 and T-ERK1/2 MAPK in vimentin-positive DCs (arrowheads) and cytokeratin-positive ITs (arrows) of control (A and C) and abruption-complicated (B and D) decidua. A and B: Total ERK1/2 MAPK is localized in DCs and ITs with similar staining in control (A) and in abruptioncomplicated (B) specimens. Inset, A: Isotype control. C and D: In contrast, expression of p-ERK1/2 in DCs is higher in abruption-complicated decidua (D), as indicated by increased nuclear staining compared with that of control decidua (C). E: HSCOREs for p-ERK1/2 by cell type (DC versus IT). Data are expressed as means \pm SEM. $n=7$ different patient tissue samples for each group.

The present study used a two-tiered approach to determine whether abruptions are accompanied by functional P4 withdrawal. Use of a primary antibody recognizing both PR-A and PR-B to perform triple immunostaining of placental sections demonstrated that, among the major resident cell types at the maternal-fetal interface, PR is localized exclusively in the nuclei of vimentin-positive DCs. Moreover, DC nuclei in abruption sections displayed significantly lower PR HSCOREs, compared with DC nuclei from gestational age-matched control specimens. Western blotting of nuclear extracts from primary leukocyte-free term DC cultures complemented these in situ observations by demonstrating that i) DCs express both PR-A and PR-B, ii) E2 enhances levels of both isoforms, iii) MPA produces a smaller increase in these levels, and iv) E2+MPA produces intermediate levels of both isoforms. These differential steroid responses are consistent with both the priming action of E2 on endometrial PR expression and the sustained expression of PR within the steroid milieu of pregnancy. ${ }^{49}$ In coincubations with E2 or E2+MPA, thrombin elicited a concentrationdependent lowering of PR-A and PR-B levels in the cultured DCs. Other experiments with term DC monolayers found that thrombin lowered steady-state PR mRNA levels and that thrombin inhibited PR receptor binding to radiolabeled $\mathrm{P} 4$ and reduced binding of $\mathrm{PR}$ to its cognate DNA elements in gel shift assays.

Assessment of PR expression was complemented by parallel measurements aimed at determining whether altered GR expression contributes to functional P4 withdrawal. Immunostaining of decidual sections revealed striking differences between PR and GR expression by DCs. Unlike the specific immunolocalization of PR in DC nuclei, immunoreactive GR was observed in nuclei of both vimentin-positive DCs and cytokeratin-positive ITs. Significantly higher GR HSCORES were observed in IT than in DC nuclei, with no significant differences noted between abruption and control placentas in either cell type. Complementing these in situ measurements, Western blotting of nuclear extracts from primary leukocytefree DC cultures indicated that GR expression is essentially constitutive. Thus, in contrast with highly regulated $\mathrm{PR}$, the GR mRNA and protein levels were unaffected by incubation with thrombin or steroids, whether added separately or together.

Viewed within the context of the present in situ and in vitro observations linking abruption-related functional P4 withdrawal with thrombin-inhibited PR expression in DCs, the established association between excess thrombin and the occurrence of abruptions points to the importance of identifying any signaling pathway or pathways mediating this thrombin effect. Thrombin augments the expression of several biochemical endpoints in different cell lines and primary cells via phosphorylated ERK $1 / 2$ or p38 MAP kinase or NF- $\kappa$ B mediation. 27,31,38 However, a literature search revealed no examples in which thrombin directly affects the expression of steroid receptors including PR and GR.

Seeking to elucidate the mechanism or mechanisms underlying our novel observation that thrombin inhibits PR but not GR expression in term DCs, we found that, in cultured term DCs, thrombin augmented levels of p-ERK1/2, but not of p-p38 MAP kinase or p-p65 NF- $\kappa$ B. Moreover, inhibition of thrombin-enhanced $p-E R K 1 / 2$ expression reversed inhibition of PR-A and PR-B expression by thrombin. Complementing these in vitro observations, immunostaining of decidual sections revealed significantly elevated levels of phosphorylated but not total ERK1/2 in DC nuclei of abruption versus gestational agematched control specimens, with no such correlation evident for ITs. Taken together, these in vitro and in situ observations indicate that thrombin down-regulates decidual PR expression via ERK1/2 phosphorylation.

A recent report from our laboratory indicated that initiation of human labor is accompanied by significantly reduced immunoreactive $\mathrm{PR}-\mathrm{A}$ and $\mathrm{PR}-\mathrm{B}$ levels in decidual cells. ${ }^{25}$ These observations complement reports that 
human parturition is accompanied by an increase in the ratio of PR-A to PR-B in myometrial cell nuclei induced by prostaglandins E2 and F2- $\alpha .{ }^{50}$ These effects are expected to promote functional P4 withdrawal, because PR-B (but not PR-A) is transcriptionally active in myometrial cells. ${ }^{51,52}$ The present study extends our previous observations of term labor-related decreased PR-A and PR-B expression in DCs to abruption-initiated PTD by demonstrating, first, that immunoreactive PR levels are significantly lower in DCs of placental sections from abruption-associated PTD versus gestational age-matched control placental sections with idiopathic PTD and, second, that thrombin, an abruption-related effector molecule generated in excess from DC-expressed TF, directly inhibits both PR mRNA and PR-A and PR-B protein expression in DCs via $p-E R K 1 / 2$. Future studies that determine whether targeting of myometrial cells by thrombin inhibits PR expression and/or induces a shift to dysfunctional PR isoform ratio dominance should increase our understanding of abruption-related functional P4 withdrawal.

Thrombin, induced by decidual cell $\mathrm{TF}^{13}$ in the setting of abruption, contributes to PPROM, preterm labor, and PTD in multiple ways. These include the aforementioned effects of thrombin on MMP and IL-8 expression in DCs, ${ }^{18,19}$ as well augmentation by thrombin of expression of MMP-9, which preferentially degrades basement membrane-type proteins in the amniochorion. ${ }^{53}$ Moreover, direct targeting of human fetal membranes by thrombin elicits changes consistent with abruption-related PPROM. Specifically, thrombin directly weakens preparations of the amniotic membrane, the major loadbearing fetal membrane component, via induction of tissue remodeling and apoptotic markers. ${ }^{54}$ Finally, in vitro and in vivo studies in the rat indicate that exogenous thrombin or thrombin formed from actively clotting blood exerts a strong uterotonic action that is independent of prostaglandin production. ${ }^{55}$ These observations suggest a mechanism to explain increased myometrial contractions in the presence of intrauterine bleeding that is consistent with the onset of preterm labor accompanying vaginal bleeding. ${ }^{56}$ Findings from the present study support the hypothesis that abruption-associated thrombin generation also initiates progestin withdrawal in the decidua, and thus may be one pathway that either initiates or contributes to the proparturition effects.

\section{Acknowledgment}

We thank Dr. Mizanur Rahman for his expert cell culture work.

\section{References}

1. Ananth CV, Peltier MR, Chavez MR, Kirby RS, Getahun D, Vintzileos AM: Recurrence of ischemic placental disease. Obstet Gynecol 2007 110:128-133

2. Harger JH, Hsing AW, Tuomala RE, Gibbs RS, Mead PB, Eschenbach DA, Knox GE, Polk BF: Risk factors for preterm premature rupture of fetal membranes: a multicenter case-control study. Am J Obstet Gynecol 1990, 163:130-137
3. Williams MA, Mittendorf R, Lieberman E, Monson RR: Adverse infant outcomes associated with first-trimester vaginal bleeding. Obstet Gynecol 1991, 78:14-18

4. Salafia CM, López-Zeno JA, Sherer DM, Whittington SS, Minior VK, Vintzileos AM: Histologic evidence of old intrauterine bleeding is more frequent in prematurity. Am J Obstet Gynecol 1995, 173:1065-1070

5. Brosens I, Pijnenborg R, Vercruysse L, Romero R: The "Great Obstetrical Syndromes" are associated with disorders of deep placentation. Am J Obstet Gynecol 2011, 204:193-201

6. Naeye RL: Maternal age, obstetric complications, and the outcome of pregnancy. Obstet Gynecol 1983, 61:210-216

7. RoquÉ H, Paidas MJ, Funai EF, Kuczynski E, Lockwood CJ: Maternal thrombophilias are not associated with early pregnancy loss. Thromb Haemost 2004, 91:290-295

8. Lykke JA, Paidas MJ, Langhoff-Roos j: Recurring complications in second pregnancy. Obstet Gynecol 2009, 113:1217-1224

9. Lockwood CJ, Krikun G, Papp C, Toth-Pal E, Markiewicz L, Wang EY Kerenyi T, Zhou X, Hausknecht V, Papp Z, Schatz F: The role of progestationally regulated stromal cell tissue factor and type-1 plasminogen activator inhibitor (PAl-1) in endometrial hemostasis and menstruation. Ann N Y Acad Sci 1994, 734:57-79

10. Mackman N, Tilley RE, Key NS: Role of the extrinsic pathway of blood coagulation in hemostasis and thrombosis. Arterioscler Thromb Vasc Biol 2007, 27:1687-1693

11. Moore KL: Formation of the bilaminar embryonic disc: second week. The developing human: clinically oriented embryology, ed 4. Philadelphia, W.B. Saunders, 1988, pp 38-49

12. Pijnenborg R, Vercruysse L, Hanssens M: The uterine spiral arteries in human pregnancy: facts and controversies. Placenta 2006, 27:939958

13. Lockwood CJ, Murk W, Kayisli UA, Buchwalder LF, Huang ST, Funai EF, Krikun G, Schatz F: Progestin and thrombin regulate tissue factor expression in human term decidual cells [Erratum appeared in $\mathrm{J}$ Clin Endocrinol Metab 2009, 94:2674 and in J Clin Endocrinol Metab 2009, 94:3620]. J Clin Endocrinol Metab 2009, 94:2164-2170

14. Pritchard JA, Wright MR: Pathogenesis of hypofibrinogenemia in placental abruption. N Engl J Med 1959, 261:218-222

15. Chaiworapongsa T, Espinoza J, Yoshimatsu J, Kim YM, Bujold E, Edwin S, Yoon BH, Romero R: Activation of coagulation system in preterm labor and preterm premature rupture of membranes. J Matern Fetal Neonatal Med 2002, 11:368-373

16. Elovitz MA, Baron J, Phillippe M: The role of thrombin in preterm parturition. Am J Obstet Gynecol 2001, 185:1059-1063

17. Rosen T, Kuczynski E, O'Neill LM, Funai EF, Lockwood CJ: Plasma levels of thrombin-antithrombin complexes predict preterm premature rupture of the fetal membranes. J Matern Fetal Neonatal Med 2001, 10:297-300

18. Mackenzie AP, Schatz F, Krikun G, Funai EF, Kadner S, Lockwood $\mathrm{CJ}$ : Mechanisms of abruption-induced premature rupture of the fetal membranes: thrombin enhanced decidual matrix metalloproteinase-3 (stromelysin-1) expression. Am J Obstet Gynecol 2004, 191:19962001

19. Rosen T, Schatz F, Kuczynski E, Lam H, Koo AB, Lockwood CJ: Thrombin-enhanced matrix metalloproteinase-1 expression: a mechanism linking placental abruption with premature rupture of the membranes. J Matern Fetal Neonatal Med 2002, 11:11-17

20. Oner C, Schatz F, Kizilay G, Murk W, Buchwalder LF, Kayisli UA, Arici A, Lockwood CJ: Progestin-inflammatory cytokine interactions affect matrix metalloproteinase- 1 and -3 expression in term decidual cells: implications for treatment of chorioamnionitis-induced preterm delivery. J Clin Endocrinol Metab 2008, 93:252-259

21. Lockwood CJ, Toti P, Arcuri F, Paidas M, Buchwalder L, Krikun G, Schatz F: Mechanisms of abruption-induced premature rupture of the fetal membranes: thrombin-enhanced interleukin-8 expression in term decidua. Am J Pathol 2005, 167:1443-1449

22. Baggiolini M, Walz A, Kunkel SL: Neutrophil-activating peptide-1/ interleukin 8, a novel cytokine that activates neutrophils. J Clin Invest 1989, 84:1045-1049

23. Thijssen $\mathrm{JH}$ : Progesterone receptors in the human uterus and their possible role in parturition. J Steroid Biochem Mol Biol 2005, 97:397400

24. Mesiano S, Chan EC, Fitter JT, Kwek K, Yeo G, Smith R: Progesterone withdrawal and estrogen activation in human parturition are coordi- 
nated by progesterone receptor A expression in the myometrium. J Clin Endocrinol Metab 2002, 87:2924-2930

25. Lockwood CJ, Stocco C, Murk W, Kayisli UA, Funai EF, Schatz F: Human labor is associated with reduced decidual cell expression of progesterone, but not glucocorticoid, receptors. J Clin Endocrinol Metab 2010, 95:2271-2275

26. Karalis K, Goodwin G, Majzoub JA: Cortisol blockade of progesterone: a possible molecular mechanism involved in the initiation of human labor. Nat Med 1996, 2:556-560

27. Lin CC, Shih $\mathrm{CH}$, Yang YL, Bien MY, Lin CH, Yu MC, Sureshbabu M, Chen BC: Thrombin induces inducible nitric oxide synthase expression via the MAPK, MSK1, and NF-kappaB signaling pathways in alveolar macrophages. Eur J Pharmacol 2011, 672:180-187

28. van Willigen G, Gorter G, Akkerman JW: Thrombopoietin increases platelet sensitivity to alpha-thrombin via activation of the ERK2-cPLA2 pathway. Thromb Haemost 2000, 83:610-616

29. Bharti AC, Aggarwal BB: Nuclear factor-kappa B and cancer: its role in prevention and therapy. Biochem Pharmacol 2002, 64:883-888

30. Wang T, Zhang X, Li JJ: The role of NF-kappaB in the regulation of cell stress responses. Int Immunopharmacol 2002, 2:1509-1520

31. Kawanami D, Matoba K, Kanazawa Y, Ishizawa S, Yokota T, Utsunomiya K: Thrombin induces MCP-1 expression through Rho-kinase and subsequent $\mathrm{p} 38 \mathrm{MAPK} / \mathrm{NF}-\mathrm{kappaB}$ signaling pathway activation in vascular endothelial cells. Biochem Biophys Res Commun 2011, 411:798-803

32. Pou J, Rebollo A, Piera L, Merlos M, Roglans N, Laguna JC, Alegret M: Tissue factor pathway inhibitor 2 is induced by thrombin in human macrophages. Biochim Biophys Acta 2011, 1813:1254-1260

33. Chang L, Karin M: Mammalian MAP kinase signalling cascades. Nature 2001, 410:37-40

34. Xia Z, Dickens M, Raingeaud J, Davis RJ, Greenberg ME: Opposing effects of ERK and JNK-p38 MAP kinases on apoptosis. Science 1995, 270:1326-1331

35. Galcheva-Gargova Z, Dérijard B, Wu IH, Davis RJ: An osmosensing signal transduction pathway in mammalian cells. Science 1994, 265: 806-808

36. Johnson GL, Lapadat R: Mitogen-activated protein kinase pathways mediated by ERK, JNK, and p38 protein kinases. Science 2002, 298:1911-1912

37. Kawano Y, Furukawa $\mathrm{Y}$, Nasu K, Narahara H: Thrombin-induced chemokine production in endometrial stromal cells. Hum Reprod 2011, 26:407-413

38. Zündorf G, Reiser G: The phosphorylation status of extracellularregulated kinase $1 / 2$ in astrocytes and neurons from rat hippocampus determines the thrombin-induced calcium release and ROS generation. J Neurochem 2011, 119:1194-1204

39. Salafia CM, Weigl C, Silberman L: The prevalence and distribution of acute placental inflammation in uncomplicated term pregnancies. Obstet Gynecol 1989, 73:383-389

40. Romero R, Yoon BH, Mazor M, Gomez R, Diamond MP, Kenney JS, Ramirez M, Fidel PL, Sorokin Y, Cotton D, Sehgal P: The diagnostic and prognostic value of amniotic fluid white blood cell count, glucose, interleukin-6, and gram stain in patients with preterm labor and intact membranes. Am J Obstet Gynecol 1993, 169:805-816
41. Mutch DG, Soper JT, Budwit-Novotny DA, Cox EB, Creasman WT, McCarty KS Sr, McCarty KS Jr: Endometrial adenocarcinoma estrogen receptor content: association of clinicopathologic features with immunohistochemical analysis compared with standard biochemical methods. Am J Obstet Gynecol 1987, 157:924-931

42. Lockwood CJ, Arcuri F, Toti P, Felice CD, Krikun G, Guller S, Buchwalder LF, Schatz F: Tumor necrosis factor-alpha and interleukin1beta regulate interleukin-8 expression in third trimester decidual cells: implications for the genesis of chorioamnionitis. Am J Pathol 2006, 169:1294-1302

43. Li X, O'Malley BW: Unfolding the action of progesterone receptors. J Biol Chem 2003, 278:39261-39264

44. Kastner P, Krust A, Turcotte B, Stropp U, Tora L, Gronemeyer H, Chambon P: Two distinct estrogen-regulated promoters generate transcripts encoding the two functionally different human progesterone receptor forms A and B. EMBO J 1990, 9:1603-1614

45. Graham JD, Clarke CL: Expression and transcriptional activity of progesterone receptor $\mathrm{A}$ and progesterone receptor $\mathrm{B}$ in mammalian cells. Breast Cancer Res 2002, 4:187-190

46. Smith R: Parturition. N Engl J Med 2007, 356:271-283

47. Gibb W, Challis JR: Mechanisms of term and preterm birth. J Obstet Gynaecol Can 2002, 24:874-883

48. Goldman S, Weiss A, Almalah I, Shalev E: Progesterone receptor expression in human decidua and fetal membranes before and after contractions: possible mechanism for functional progesterone withdrawal. Mol Hum Reprod 2005, 11:269-277

49. Eckert RL, Katzenellenbogen BS: Human endometrial cells in primary tissue culture: modulation of the progesterone receptor level by natural and synthetic estrogens in vitro. J Clin Endocrinol Metab 1981, 52:699-708

50. Madsen G, Zakar T, Ku CY, Sanborn BM, Smith R, Mesiano S: Prostaglandins differentially modulate progesterone receptor-A and -B expression in human myometrial cells: evidence for prostaglandininduced functional progesterone withdrawal. J Clin Endocrinol Metab 2004, 89:1010-1013

51. Mesiano S: Myometrial progesterone responsiveness. Semin Reprod Med 2007, 25:5-13

52. Zakar T, Mesiano S: How does progesterone relax the uterus in pregnancy? N Engl J Med 2011, 364:972-973

53. Stephenson CD, Lockwood CJ, Ma Y, Guller S: Thrombin-dependent regulation of matrix metalloproteinase (MMP)- 9 levels in human fetal membranes. J Matern Fetal Neonatal Med 2005, 18:17-22

54. Kumar D, Schatz F, Moore RM, Mercer BM, Rangaswamy N, Mansour $\mathrm{JM}$, Lockwood CJ, Moore JJ: The effects of thrombin and cytokines upon the biomechanics and remodeling of isolated amnion membrane, in vitro. Placenta 2011, 32:206-213

55. Phillippe M, Elovitz M, Saunders T: Thrombin-stimulated uterine contractions in the pregnant and nonpregnant rat. J Soc Gynecol Investig 2001, 8:260-265

56. Elovitz MA, Saunders T, Ascher-Landsberg J, Phillippe M: Effects of thrombin on myometrial contractions in vitro and in vivo. Am J Obstet Gynecol 2000, 183:799-804 